\title{
Gregorio de Nisa y la visión mística "Como un solo ojo, mirando al único bien"
}

\author{
EVA REYES-GACITÚA* \\ Universidad Católica del Norte-Antofagasta (Chile) \\ ereyesg@ucn.cl
}

\begin{abstract}
Resumen
El presente artículo pretende poner de relieve a partir de la obra In Canticum canticorum de Gregorio de Nisa, el recorrido que el autor realiza en torno al tema de la visión mística. De esta manera se podrá analizar algunos conceptos que lo comprenden: luz y su antítesis noche; así como también detenerse en la formulación de los términos ojos-visión; lo cual nos remitirá a la pregunta, ¿qué es lo que se ve? y/o ¿quiénes contemplan a Dios como El es? De este modo, la contemplación en la obra del Niseno obtendrá alcances significativos desde una lectura antropológica cristiana.
\end{abstract}

Palabras clave: Cantar de los Cantares, razón, luz, ojos.

\section{Gregory of Nyssa and mystic vision. "As just one eye looking at the only good"}

\begin{abstract}
This paper intends to highlight, from Gregory of Nyssa's In Canticum canticorum, the author's journey around the issue of mystic vision. In this way, some of his concepts can be analyzed: light and its antithesis night, along with making a stop in the form ulation of the terms eyes-vision, which will lead us to the question, what is that which is seen? and/or, who contemplates God as $\mathrm{He}$ is? So, contemplation in the work of the Nicene will have meaningful approaches from a Christian anthropological reading.
\end{abstract}

Key words: Song of Songs, reason, light, eyes.

\footnotetext{
* Doctora en Teología por la Pontificia Universidad Católica de Chile. Actualmente académica e investigadora en la Universidad Católica del Norte, en su Casa Central de Antofagasta (Chile). Miembro de la Asociación Internacional de Estudios Patrísticos AIEP. Autora de varias publicaciones: "Lo busqué y no lo hallé, lo llamé y no me respondió'. Pensar una lectura a partir del Comcant de Gregorio de Nisa y la cuestión hermenéutica de Paul Ricoeur" (2016); "Hacia la comprensión de Quem diligit 'anima mea’ en la teología mística de Guillermo de Saint-Thierry” (2017).
} 
INTRODUCCIÓN ${ }^{1}$

El papa Benedicto XVI en su Catequesis del 29 de agosto de 2007 presentaba a Gregorio de Nisa como un hombre de carácter meditativo, con gran capacidad de reflexión y de "una inteligencia despierta" (Benedicto XVI, 2007:1). Allí, el entonces Papa afirmaba que la vida del Obispo de Nisa no sólo había sido una academia, sino también toda una experiencia espiritual, como "padre de la mística" había trazado el camino que los cristianos debían recorrer para emprender el encuentro con Dios.

En esta línea, el especialista Johan Quasten confirma su aporte a la teología "A él se debe después de Orígenes, la primera exposición orgánica y sistemática de la fe cristiana. Sus especulaciones doctrinales tienen un alcance muy superior a las controversias de su tiempo y son una contribución al progreso de la teología como tal" (Quasten, 2012: cap 3. Gregorio de Nisa).

Su nacimiento se ubica entre los años 335-340 y su muerte en el 394. Fue profesor de retórica, no exento de dificultades llegó a ser Obispo de Nisa a partir del 372 y participará activamente durante el segundo Concilio Ecuménico de Constantinopla en el 381. Su actividad literaria se desarrolla en los años de madurez 379-394. Fue uno de los "tres grandes Capadocios", donde a Basilio de Cesarea se le conoció como hombre de acción; a Gregorio Nacianceno como maestro de oral y Gregorio de Nisa fue destacado como el pensador (Quasten, 2012: cap 3. Los Padres Capadocios).

El presente artículo intenta colocar de relieve a partir de la obra In Canticum canticorum de Gregorio de Nisa, el recorrido que el autor elabora en torno al tema de la visión mística. El campo semántico de los términos fã $\zeta$ y ỏ $\varphi \theta \alpha \lambda \mu$ o $\varsigma$ permitirá establecer una lectura complexiva del texto. De este modo se indagará en la pregunta ¿qué es lo que se ve? y/o ¿quiénes contemplan a Dios como El es? Cuatro ejes posibilitarán avanzar a la pregunta enunciada: primero, la participación de los sentidos, destacando las expresiones de la luz y su antítesis noche. Segundo, examinar el órgano de la visión, a partir del vocablo ojo. Tercero, explorar el simbolismo de "los ojos como paloma" y finalmente detenernos en la propuesta del In Canticum ver "el rostro de Aquel". La

\footnotetext{
1 Parte de este trabajo fue presentado en el X Seminario de Estudios Patrísticos, organizado por las Facultades de Teología y Filosofía de la Pontificia Universidad Católica de Chile. Realizado entre los días 29 de agosto al 2 de septiembre 2017. El texto ha sido revisado y ampliado en vistas a su publicación.
} 
conclusión permitirá - a modo de un iceberg - concretar la centralidad del problema en cuestión.

\section{PARTICIPACIÓN DE LOS SENTIDOS: LUZ Y NoCHE}

La luz fõ $\varsigma$, aquella que desintegra la sombra (Campos, 2017: 237) y abre la inteligencia al sentido (Acosta, 2017: 237), ha sido desde antiguo el criterio rector del pensamiento y de la conducta humana. Aristóteles comparaba la luz - que de lo alto hace llegar los colores-, con la acción del entendimiento activo sobre el alma humana. Los estoicos advirtieron que para el reconocimiento de la verdad fueron dadas - como luz de la naturaleza - la facultad y la representación que a través de ella se genera. A su vez Plotino relacionó el Bien con aquella luz que ilumina al intelecto (Abbagnano, 1991: 761).

Análogamente para el Obispo de Nisa la luz adviene del levante al poniente, ilumina las tinieblas y no conoce sombra. La presenta en cuanto "luz verdadera" (CCEE III: 61) ${ }^{2}$, haciéndola extensiva a los vocablos de vida, justicia y sabiduría. El In Canticum ${ }^{3}$ la comprende en términos salvíficos: por esta luz, la esposa podrá ser totalmente configurada, ya que a partir de la invitación del Verbo, se acercará volviéndose hermosa. Este tránsito será posible en cuanto paloma sea iluminada, ya que en ese momento comprenderá que la roca es Cristo. Será el tiempo en el cual no habrá necesidad de ventanas, porque llegará la luz y con sus rayos evangélicos iluminará a todo el mundo. Por ello en términos de la esposa "no hay mejor luz que a mediodía".

De este modo Gregorio de Nisa, subraya que la naturaleza humana es imagen de la luz, permaneciendo "refulgente por su semejanza con la belleza ejemplar" (CCEE II: 36). Es más, ¿ha querido señalar que al mirar la luz verdadera el hombre imita a Aquel que resplandece en él? Entonces, se está ante la maravilla de la inhabitación divina, es decir, en el hecho paradójico de Aquel que contiene en sí todo, se deja contener por su criatura:

Eres semejante a la hermosura en que nada hay perecedero. Es relevante figura del Dios verdadero, palacio de la bienaventuranza, retrato lleno de

\footnotetext{
2 Seguimos la edición del Comentario al Cantar de los Cantares (De Nisa, 1993) preparada por Teodoro H. Martín-Luna. En adelante CCEE, número de Homilía y página.

Texto fuente de In Canticum Canticorum (Nysseni, 1986). En adelante citado como GNO, Volumen VI, página, seguido de parágrafo.
} 
luz verdadera. Al mirarla, en ella se transforma, imita a aquel que resplandece; su luz se refleja en tu pureza (CCEE II: 44) 4 .

Entonces la esposa se ha vuelto hermosa, iluminada con la luz de la verdad. Con agua se ha quitado la negrura de la ignominia (CCEE VI: 173) y por esta razón el esposo la elogia repetidamente:

Te has hecho hermosa por acercarte a mi luz; por la proximidad participas de esta hermosura. ¡Qué hermosa eres, amada mía! (CCEE IV: 65)5.

Según el autor como la luz va por todas partes, el Espíritu Santo sopla donde quiere, dando luz a los que saben de dónde vienen y adónde van (CCEE VII: 131). Así, el hombre una vez transformado por la gracia, se renueva a imagen del Creador. En esta perspectiva afirma el Niseno, se puede comprender las palabras del evangelio de Mateo 5, 14: ustedes son la luz del mundo (CCEE XIII: 207). Del mismo modo, el episodio bíblico de Jesús y Felipe portaría este sentido, donde a través de un "sígueme" se acercó a la luz verdadera participando de ella como una antorcha y llevándola a Natanael como si se la pusiera delante de sus ojos (CCEE XV: 232).

Esta es la luz surgida desde la voz del Verbo (CCEE VIII: 139) y es así como Dios comienza apareciéndose al gran Moisés: $\tau \tilde{\varphi} \mu \varepsilon \gamma \alpha \dot{\lambda} \omega$

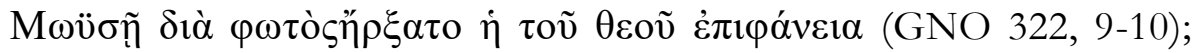

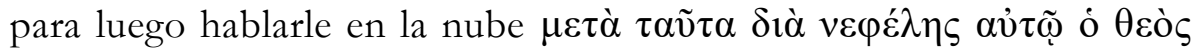
$\delta 1 \alpha \lambda \varepsilon ́ \gamma \varepsilon \tau \alpha \mathbf{l}$ (GNO 322, 10-11). Se trata de un "conocimiento nuevo, como una nube luminosa que alumbra lo que miramos" (CCEE XI: 172). Más tarde devendrá con Dionisio la comprensión de la tiniebla supraluminosa. Se trata de una bella y profunda expresión que denota la reciprocidad del encuentro entre Dios y el hombre. Para el autor, la experiencia de la luminosidad permite al hombre ubicarlo en un nuevo estadio, teniendo cerca aquellas cosas que antes le fueron ocultas (CCEE XI, 172). No obstante, sólo cuando Moisés sea más sublime y

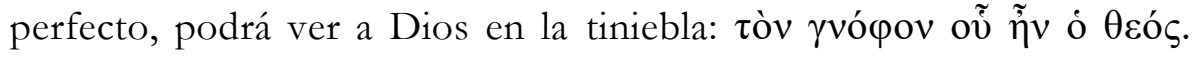
Gregorio expresa que el hombre situado en este camino subirá a lo más

4 In Cant. GNO VI 68, 6 - 10: $\tau$ :

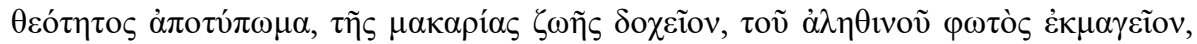

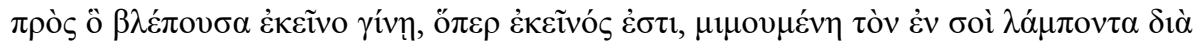

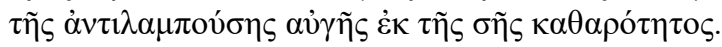

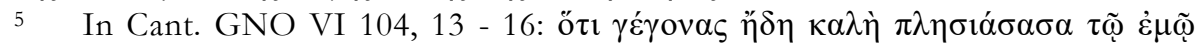

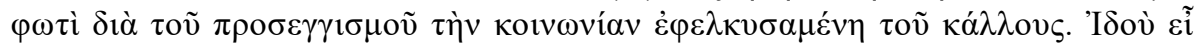
$\kappa \alpha \lambda \dot{\eta}, \varphi \eta \sigma i ́ v, \dot{\eta} \pi \lambda \eta \sigma i ́ o v ~ \mu o v$. 
alto, dejando todo aquello que le entretenga. De este modo vivirá en los umbrales del conocimiento de Dios. Para entonces dejará afuera todo lo que puede ver y comprender. Sólo podrá contemplar lo que es invisible e incomprensible. Como dice la Escritura acerca de Moisés: "Entró dentro de la nube donde estaba Dios" (CCEE XI: 172). El concepto $v \varepsilon \varphi \varepsilon ́ \lambda \eta$, se sitúa como símbolo privilegiado del misterio de la presencia divina. Manifiesta a Dios, al mismo tiempo que lo vela. En la expresión de Ex 16,10: "la gloria de Yahvé se apareció en la nube", se asocia con la gloria que es fuego Núm 9,15 (León-Dufour, 1965: 524). Esta expresión del misterio es también recogida por el Obispo de Nisa al comentar Lc 1,35:

El poder del Altísimo la cubrió con una nube y la antorcha nupcial del Espíritu santo llenó de luz el tálamo de pureza virginal (CCEE XIII: $208)^{6}$.

En el Antiguo Testamento, la nube manifiesta la presencia de Dios y la gloria de su Hijo (León-Dufour, 1965: 525).

Sin límite de crecimiento la esposa buscará constantemente el bien mayor y superabundante, a Aquel que es mayor y está por encima de todo bien. "Participación que el bien creado puede aumentar con tendencia al bien mayor" (CCEE VI: 100). Esta es la comprensión que realiza el Niseno al subrayar que el alma es atraída por el bien del cual participa. Se trata de la participación de la misma divinidad, a modo que el mismo Verbo-Dios es el que posibilita esta singular acción (CCEE III: 47). De este modo ella podrá salir de sí, crecer a ejemplo del modelo. "El alma se supera a sí misma y aumenta por la adaptación a aquello de que participa" (CCEE V: 92). Será su propósito en el sentido de Flp 3, 13: "Olvido lo que dejé atrás y me lanzo a lo que está por delante, corriendo hacia la meta". En la raíz de esta comprensión se encuentra el término $\varepsilon \varphi \pi \varepsilon \varpi \kappa \tau \alpha \sigma \imath \sim$ donde San Pablo compara su vida interior a la del corredor, siempre en tensión hacia la meta, intentando superarse a sí mismo. El Niseno lo describe de la siguiente manera: "Al que se levanta le queda siempre la posibilidad de subir más" (CCEE V: 93). En este sentido, Gregorio supondrá una radical novedad con respecto al pensamiento heleno. En efecto, para los griegos, la perfección humana es sinónimo de quietud y acabamiento, para Gregorio consiste en el progreso y la tensión sin fin hacia el bien. Esta es considerada como

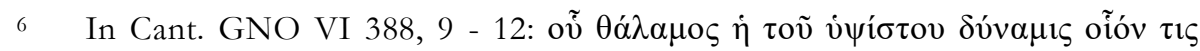

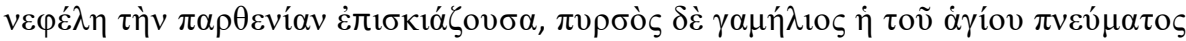

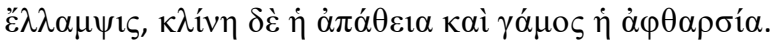


la contemplación de Dios en su cima más alta, éxtasis constante de la superación de sí mismo (Mateo-Seco, 1997). No se trata de un permanente status viatoris sino, el destino de una meta teniendo en cuenta que el "término de lo andado es punto de partida para lo más alto a que camina" (CCEE VI: 102).

Ella se apresura por llegar a la inteligencia de Dios, sin embargo, estando en el bien se lamenta de que lo necesita. El Niseno indicará que la esposa ama a Dios con toda su alma y con todas sus fuerzas y Dios es el esposo en el cual se encuentran los mayores bienes esperados. Con esto enseña que la perfección se encuentra distante, pues apenas ha pasado los umbrales. Engalanada con lo que es perfecto, descansa como si estuviese ya en el lecho de las cosas que comprende. Empero, se halla dentro de lo que no se ve, es decir, perdidos los sentidos, porque la envuelve la noche (CCEE VI: 103). Es decir, en una "espantosa belleza que hiere" (Rodríguez, 2017: 297).

Este es el tiempo en que el Esposo se acerca sin dejarse ver, entonces el hombre se encuentra ante la paradoja de este singular momento, donde es más visible el invisible. Por tanto, hará que el alma sienta su presencia, pero no deja que el entendimiento lo comprenda. Por ello, Gregorio denomina noche al tiempo de dormir, y también lo concibe como contemplación de lo que se ve, a semejanza de Moisés que entró en la tiniebla donde estaba Dios. Entonces, envuelta en la noche la esposa busca al que se oculta en las tinieblas, ama al deseado; pero el amado vuela y no podrá alcanzarle el pensamiento. De modo que de noche le buscará en el lecho: "En mi lecho, por las noches, he buscado al amado de mi alma" (CCEE VI: 105).

Es destacable la relación análoga que establece el autor en torno a la búsqueda del alma con la noche, ¿cómo en la noche es más visible el invisible? Una vez más Gregorio subraya el siguiente dinamismo presente en todo el In Canticum, a saber, el alma siente su presencia, pero no es posible que el entendimiento la comprenda. De allí el alto alcance que obtienen los sentidos de la esposa: vista, oído, olfato, tacto y gusto. Los cuales anticipan de algún modo la presencia del amado. Gregorio sostiene que estas aproximaciones son una introducción en el misterio y por ello envuelve al alma con la noche (CCEE XI: 173).

En síntesis, la esposa en la medida que conoce aumenta en ella el deseo de ver, no obstante, este le será otorgado en la contemplación. La luz y la noche la preparan en la dinámica de mirar aquello que permanece oculto. Sin embargo, los sentidos la introducen hacia una nueva comprensión; donde los ojos tendrán cierta preeminencia. 


\section{FIJAR LOS OJOS EN EL ÚNICO BIEN}

El Obispo de Nisa afirma que vemos el rostro y alma de las personas mirando a las pupilas de sus ojos. En este aspecto, los especialistas de ciencias naturales afirman que el ojo aumenta su visión al ser estimulado por la visibilidad de las cosas. Sin embargo, la esposa no puede fijar los ojos en el Verbo de Dios como no se puede mirar directamente el círculo del sol (CCEE III: 57). Ahora bien, El es para nosotros alegría de los ojos porque los ilumina (CCEE III: 72). En virtud de ello ha de comprenderse que los ojos de la esposa son palomas, ya que la paloma es hermosa por sí misma y se hace luz al acercarse a la luz. Con ello Gregorio destaca la identificación de la creatura con el Creador, a partir de la idea de la semejanza, proveniente de una larga tradición "Lo semejante es conocido por lo semejante" (Aristóteles, 2011: I, 404 b17). Expresión que desarrollará Gregorio en vistas a la divinización del hombre. Además, agrega que en esta luz también estaba como en imagen la paloma, refiriéndose al Espíritu Santo (CCEE V: 88). Para el Niseno, coinciden los deseos de la esposa con las palabras de Simeón: "Ahora, Señor, puedes, según tu palabra, dejar que tu siervo se vaya en paz, porque han visto mis ojos tu salvación” Lc 2, 29 (CCEE V: 95). De este modo, Gregorio refuerza el sentido teologal allí contenido "parecen palomas los ojos por su hermosura" (CCEE VI: 101).

Así la esposa comenzará a ver al deseado, que aparece ante sus ojos de nueva forma revestido (CCEE VI: 102). Sus ojos son como espada que miran siempre a Dios para contemplar lo que es recto, sin que ninguna cosa manche su visión (CCEE VI: 110). Según el autor, el alma cuando se deleita en la contemplación, se desentiende de cuanto le pueda causar placer por los sentidos. Entonces, liberada de todo sentido corporal, desnuda y pura la mente, velará esperando la visita de Dios (CCEE X: 168).

Así, en la contemplación el rey Salomón —el de sabiduría inmensa, el rey que juzga con justicia y es hijo de David-afirma:

¡Qué bella eres, amada mía, qué bella eres! Palomas son tus ojos a través de tu velo (CCEE VII: 113) 7 .

Por esta razón la contemplación en Gregorio posibilita la configuración con Aquel a quien se contempla (CCEE V: 86).

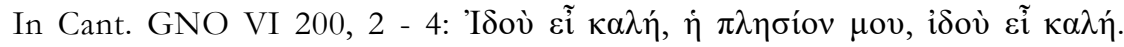

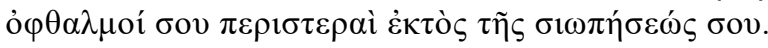


Según Gregorio, los ojos son el sentido más importante; se recibe la luz, conociendo lo favorable y lo adverso. Prueba de ello es que se encuentran colocados sobre los otros sentidos (CCEE VII: 121), guiando al cuerpo (CCEE XIII: 212). Explicando las Escrituras el Niseno indica: Samuel era un ojo, por ello lo llamaban el vidente. También ojo era Ezequiel, a quien Dios hizo espejo para salvar a los que custodiaba. Ojo también fue Miqueas y Moisés, llamado el observador, pues lo consideraban como Dios. Son ojos quienes guían al pueblo y aquellos que en el cuerpo de la Iglesia han sido puestos como supervisores. En el libro de los profetas Dios denomina ojos a los que tienen la misión de mirar e inspeccionar (CCEE XIII: 212). Mas, quienes han sido dispuestos para estar en lugar de los ojos, ejercen su oficio en santidad, lavando todo mal de ellos en la práctica de la virtud (CCEE XIII: 212).

Para nuestro autor, es perfecta la alabanza tributada a los ojos de la Iglesia, porque de esta manera no se refleja en ella ninguna imagen falsa, ningún error (CCEE XIII: 213). Estos son los ojos que miran al sol de justicia y ven con claridad (CCEE VII: 121). A modo análogo subraya que lo propio de los ojos es conocer al amigo y al enemigo, lo que se plasma en la enseñanza: amar de corazón al amigo y guardarse del enemigo. Gregorio coloca en alto grado al que enseña pues hace de guía y son como ojos que iluminan a los demás (CCEE VII: 122).

Por estas razones en el Cantar 4,1 el Verbo ensalza la hermosura de la esposa diciendo: ¡Palomas son tus ojos! Es decir, disfruta de buenos ojos quien permanece en el bien, procediendo con sencillez e inocencia (CCEE VII: 122). Por ello la esposa también dirá: Palomas son tus ojos. Porque los ojos pueden ver las cosas visibles, cuando se presentan ante una pupila limpia. Entonces allí, necesariamente verá algo, recibirá su forma en el ojo, grabando la imagen, como ocurre en el espejo. Gregorio se encuentra destacando el alto compromiso de quien tiene el oficio de ver en la Iglesia, logrando en él el ejercicio de una vida espiritual. Entonces, visión y vida se configuran por la gracia del Espíritu Santo. Por esta razón, el Espíritu Santo es paloma (CCEE VII: 122).

Ahora bien, se dice que ambos ojos son dignos de alabanza pues por ellos se perfecciona el hombre interior y exteriormente (CCEE VII: 122). A modo semejante, los ojos pueden discernir con precisión el lirio de la espina, elegir lo que conviene y rechazar lo caduco (CCEE VII: 132). Asimismo, se dice que el ojo es puro en cuanto se abre a la naturaleza del bien y puede llegar a contemplar la naturaleza eterna e inmutable, es decir, al Padre, al Hijo unigénito, y al Espíritu Santo (CCEE VIII: 141). El Niseno apoyado en la teología dogmática, destaca aquello 
que es posible contemplar en una naturaleza, sin que haya en ella separación por la diferencia de las hipóstasis. Expresión de la unidad en las tres Personas, designada en el Concilio de Nicea del 325 a partir del

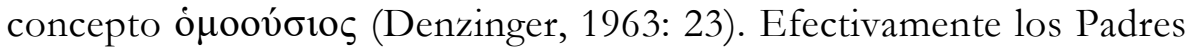
Capadocios han sido reconocidos por recoger la tradición anterior para dar cuenta de la unidad y la Trinidad.

Gregorio previene sobre el peligro de encontrarse en la dispersión, algunos con diversos ojos no tienen la vista fija en aquello que permanece. Por enfermedad de los ojos, lo que es uno se puede ver en fragmentos. Ciertamente algunos afirman ver mucho y por las muchas cosas no ven nada. Según el autor, quienes han visto a Dios y vuelven a divagar por visiones materiales se disipan en fantasías (CCEE VIII: 141). Ahora, aquel que tiene vista aguda y perspicacia, como un solo ojo, mira al único bien (CCEE VIII: 141) ${ }^{8}$ ¿ ¿Qué ha querido expresar? sino destacar que teniendo un solo ojo, una sola alma, el hombre estará centrado en una sola cosa, de manera que ninguna otra afición lo seduzca. Incluso, el afecto estará concentrado en aquel que es verdaderamente bueno (CCEE VIII: 142). Reminiscencia de 1 Timoteo 2,5: "Porque hay un solo Dios, y también un solo mediador entre Dios y los hombres". Esta noción de mediación ofrece al Niseno uno de los mejores argumentos contra Eunomio quien reduce a Cristo a mera criatura, aunque la más excelente (Mateo-Seco, 1990: 175). Particularmente la teología mística de Gregorio es cristocéntrica, subyace en cada movimiento del In Canticum la unión del alma con el Verbo, prefigura de la unión del Verbo y la humanidad.

De ahí la recomendación de mirar con los ojos del alma (CCEE X: 160); a fin de contemplar los dones verdaderos. De este modo llegará el día en que la esposa subirá más alto y se gloriará diciendo: Yo dormía pero mi corazón velaba: Cantar 5,1-2. Vela esperando la visita de Dios y su cuerpo duerme, es decir no la turban los sentidos y será el momento en el que se dispone a vivir sola, consigo misma. Este es el tiempo en que los ojos duermen porque ya no miran, es decir no se distraen; "pues la perfección del alma no se siente atraída por nada de lo que entra por los ojos" (CCEE X: 168). En consecuencia, podrá fijar sus ojos en el único bien, configurándose con aquel a quien contempla (CCEE V: 88). Gabriel Horn (1927), ha afirmado que los padres del siglo III y IV no han podido ignorar un dogma de los neo-platónicos y de Plotino en particular; el cual hace referencia a la idea de la liberación del alma y la fuga del mundo carnal. Entonces, la conversión al mundo espiritual

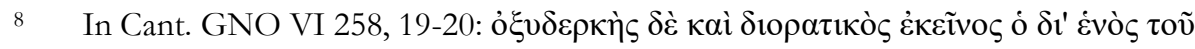
$\tau \tilde{\eta} \varsigma \psi v \chi \tilde{\eta} \varsigma$ ỏ $\varphi \theta \alpha \lambda \mu$ õ $\pi \rho \grave{s} \varsigma \mu$ óvov $\tau$ ò $\alpha \gamma \alpha \theta$ òv $\beta \lambda \varepsilon \dot{\pi} \pi \omega v$. 
ocurre en cuanto el alma puede llegar a la bienaventurada "apatía" del mundo y al silencio de las pasiones.

Por tanto, Gregorio de Nisa no es ajeno a la interpretación de las Escrituras en este sentido, claramente explicitado en el In Canticum I. Por consiguiente, aquellos que buscan la vida de arriba deben cuidarse ante el sueño y permanecer en actitud vigilante "sin pegar el ojo frente al que engaña las almas y pone asechanzas a la verdad" (CCEE XI: 169). Pues también un pesado sueño impide ver con claridad:

Sacudamos de nuestros ojos este pesado sueño y deje la mente esa manera de ver, no sea que afanándonos por tales cosas perdamos las que tienen verdadera consistencia (CCEE XI: 169-170)9 .

Entonces, los que esperan que el Señor vuelva de las bodas; se encuentran con los ojos puestos en las puertas del cielo para que el rey, al regresar de las nupcias, los lleve a la gloria celestial (CCEE XI: 170). Así reza el Salmo 19,6 “cómo esposo que sale de su tálamo”. Sólo allí acontecerá el momento de los desposorios una vez que místicamente se hubiese transformado (CCEE XI: 170).

Del mismo modo, la esposa una vez que se ha quitado el velo, ha abierto los ojos del alma, pudiendo contemplar la verdad (CCEE XIII: 204). En virtud de ello llegará el momento en el cual contempla con ojos puros la hermosura inefable del esposo (CCEE XIII: 205). Así lo dice el evangelio de Juan: "Lo que hemos visto con nuestros ojos, lo que contemplamos y tocaron nuestras manos acerca de la Palabra de vida" (1 Jn 1,1).

Finalmente, para Gregorio de Nisa el simbolismo de los ojos es el más importante, por ello lo ubica sobre los otros sentidos. Aunque la esposa no pueda fijar los ojos en el Verbo, podrá ver al deseado. Por él recibe la luz y disfruta de buenos ojos permaneciendo en el bien. Entonces, su mirada puede llegar a ser una, teniendo un solo ojo, una sola alma de modo que pueda vivir centrada en una sola cosa; en cuanto hay un solo Dios, y también un solo mediador.

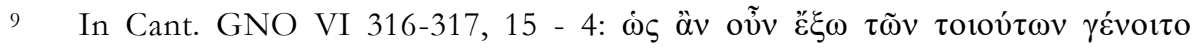

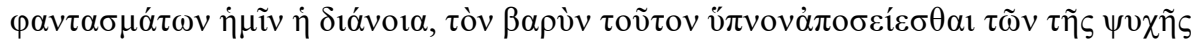

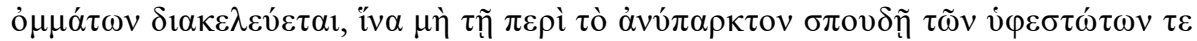

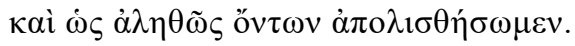




\section{SUS OJOS COMO PALOMAS}

Gregorio ha destacado que si el ojo se hace puro como el candor de la paloma entonces podrá acercarse al bien Amado. Allí podrá advertir que en la pupila de sus ojos están los de la esposa como palomas. El Obispo de Nisa ha querido subrayar el alto alcance de la mediación operada por Cristo, por ello los ojos de la esposa una vez que son palomas, podrán mirar al rostro del esposo (CCEE III: 66), en este sentido ella afirma:

Pues si tú no te hubieses hecho hombre velando los rayos luminosos de tu divinidad con tu forma de esclavo, ¿quién habría podido poner en ti los ojos? "Nadie puede ver a Dios y seguir viviendo" (CCEE IV: 67)10.

Para Gregorio el significado de estas palabras está por encima de lo que podemos comprender (CCEE XIII: 211) y una vez más los ojos de la esposa son comparados con la sencillez de la paloma. Bellamente ha sido expresado por In Canticum 5,12:

Sus ojos como palomas junto a los arroyos, bañándose en leche, posadas junto a un estanque (CCEE XIII: 199 y 206) ${ }^{11}$.

A saber, los ojos de la esposa contemplan la verdad, no admite espectros ni imágenes falsas. Por eso el alma perfecta ha resuelto lavar los ojos con leche, buen remedio para su purificación (CCEE XIII: 213). Además, aprende cómo puede embellecer el ojo de manera que su vista corresponda a la elegancia del que es cabeza de oro (CCEE XIII: 213). Habrá entonces, que posar los ojos junto a las corrientes de aguas espirituales, lavarse con leche que excluye del error y proceder con sencillez de paloma (CCEE XIV: 216). Para el Obispo de Nisa sólo la sencillez previene de la arrogancia, que finalmente priva al hombre de ver bien (CCEE XIII: 214). La comparación del agua y de la leche en relación con los ojos significa introducirse en un nuevo orden, conocimiento de la verdad y del bien:

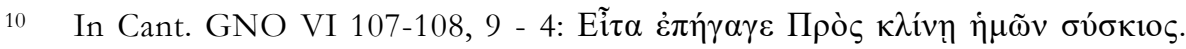

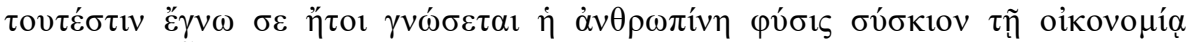

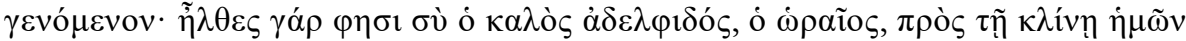

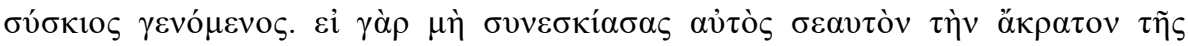

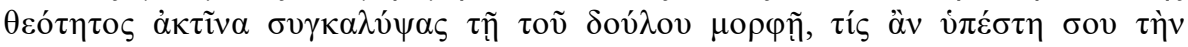

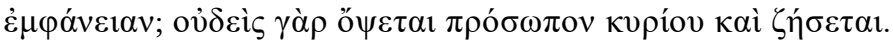

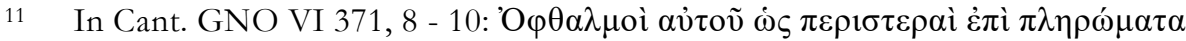

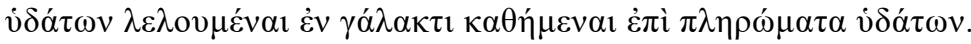


El dictamen del Señor es veraz, sabiduría del sencillo. Claro el mandamiento del Señor, luz de los ojos (CCEE XIV: 217) ${ }^{12}$.

Según el Niseno los ojos se despojan de la materia cuando por el bautismo se caen las escamas (CCEE XIV: 217). Reminiscencia del libro de los Hechos de los Apóstoles, donde Ananías se dirige a Saulo "me ha enviado a ti el Señor Jesús, el que se te apareció en el camino por donde venías, para que recobres la vista y te llenes del Espíritu Santo. Al instante cayeron de sus ojos una especie de escamas y recobró la vista; se levantó y fue bautizado". Esta perícopa se inserta en el relato de la vocación de Saulo: 9, 1-19 y es posible destacar "lo envolvió una luz venida del cielo", "los hombres que iban con él se habían detenido mudos de espanto, pues oían la voz, pero no veían a nadie", "Saulo se levantó del suelo, y, aunque tenía sus ojos bien abiertos, no veía nada", "Pasó tres días sin ver...". Para Gregorio aquel que está lleno de gracia, le será posible ver la hermosura del esposo, entonces podrá mirar su rostro, pues "nadie puede decir: ¡Jesús es el Señor! sino por el influjo del Espíritu Santo" (1 Cor 12,3). De ahí que, nuestro autor sirviéndose de una cita de 1 Cor 12,21 afirma: "No puede el ojo decir a la mano: no te necesito". Esto quiere decir que el valor de los ojos, se coloca de manifiesto por las obras que dan testimonio de su agudeza (CCEE XIV: 219). Por ende, insta a separarse de toda afición, por cuanto exhorta: "No pongamos nuestros ojos en las cosas visibles porque lo visible pasa, pero lo invisible es eterno" 2 Cor 4,18 (CCEE XIV: 221). Se trata de una buena comparación para que el corazón mire hacia lo alto, allí encuentre deleite y consiga su tesoro. Gregorio enfatiza que el hombre no se cansará de cumplir los mandamientos divinos, pues se recrea con la esperanza del cielo colocados en los ojos del alma (CCEE XIV: 223). No obstante, llegará el momento en que el Verbo dirá a la esposa:

Hermosa eres, amada mía como Tirsá, encantadora como Jerusalén, imponente como un ejército ordenado. Retira de mí tus ojos, porque me subyugan (CCEE XV: 236) ${ }^{13}$.

Para Gregorio este es el momento en que el alma - por sus esfuerzos- se encuentra al borde del milagro. Quiere decir que Dios el Altísimo, el que está en el seno del Padre, se ha hecho carne y sangre. Mas,

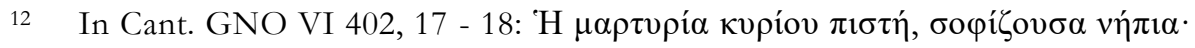

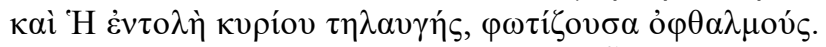

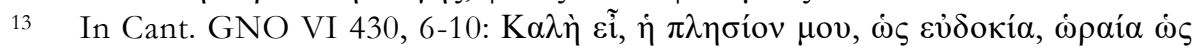

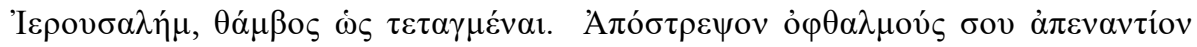

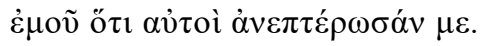


la esposa se ha configurado frente a su hermosura. En esto consiste su majestuosa belleza (CCEE XIV: 237). Gregorio evoca el sentido de correspondencia entre el esposo y la esposa, en cuanto la hermosura del alma le ha sido otorgada por el Señor. Esta relación para el autor es comprendida a partir de la adopción filial expresada en la redención de Cristo. Los textos bíblicos lo confirman en la exégesis de Flp 2,7: "se despojó de sí mismo tomando condición de siervo", 1 Tim 2,6: "se entregó a sí mismo como rescate por la vida del mundo" y 2 Cor 8,9: "Siendo rico, por nosotros se hizo pobre a fin de que nos enriqueciéramos con su pobreza". En consecuencia, la esposa tiene su belleza por aquel que en ella vive y ahora es la que porta dentro de sí aquel a quien nadie puede poner límite (CCEE XV: 237). Esta es la semejanza con la naturaleza divina, donde la mirada de Dios es gracia para la esposa (CCEE XV: 239). Gregorio resalta que Dios ha mirado al hombre con ojos de benignidad restableciéndolo tras el pecado y devolviéndolo al estado original. Así llega el momento en que la esposa señala:

Esto me dan tus ojos: tener otra vez alas y por la virtud recuperar las alas de aquel que es como una paloma. El hace que yo pueda volar y a la vez descansar en su paz como el Señor descansó después de la creación (CCEE XV: 240) ${ }^{14}$.

Según el Niseno, Dios creó todas las cosas dándoles un sentido de finalidad y perfección; la salvación es la que recupera la unidad. De este modo, los hombres han sido llamados a estar unidos en el uno y único bien con la perfección de la paloma (CCEE XV: 248).

En suma, Gregorio ha destacado que si el ojo se hace puro como el candor de la paloma podrá acercarse al bien Amado. Es decir, aquel que está lleno de gracia, le será posible ver la hermosura del esposo, y podrá advertir que en la pupila de sus ojos están los de la esposa como palomas; recibiendo la semejanza de aquello en que fija sus ojos. Bajo este simbolismo el autor ha destacado el alto alcance de la mediación operada por Cristo.

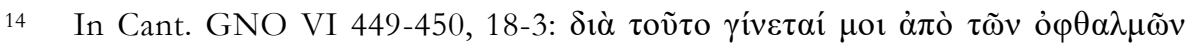

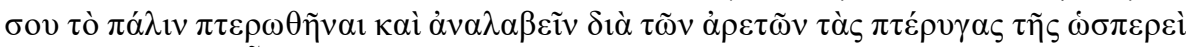

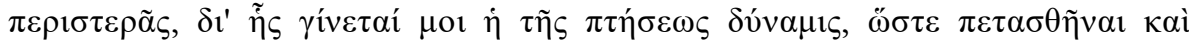

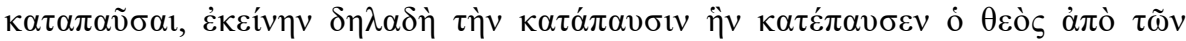

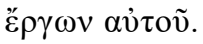


4. VER EL ROSTRO DE AQUEL

Llegamos al núcleo de la formulación filosófica teológica de Gregorio de Nisa, respecto la comprensibilidad divina. Puesto que la naturaleza inmensa de Dios no puede ser comprendida plenamente. Toda capacidad de reflexión no puede tocar la naturaleza misma del Verbo. Sin embargo, ella desea ver el rostro:

Dulce es tu voz que me llega por la ventana, pero la vista de tu presencia será mucho más amable (CCEE V: 95) ${ }^{15}$.

A Dios nadie le ha visto, ni puede ver ni conocer (CCEE III:55). A modo de ejemplo cita al gran Pablo, el que llevado hasta el tercer cielo, no entendió lo que veía (CCEE V: 82). Muéstrame tu rostro: Cantar 2,14; será la petición constante de la esposa: "muéstrate a mí sin cejales para que yo esté en la roca del evangelio” (CCEE V: 95). Para Gregorio equivale a decir, que la esposa ya no desea que el esposo le hable a través de los profetas y la ley. El texto afirma: "vedle ya que se para detrás de nuestra cerca, mirando por las ventanas, atisbando por las rejas" (CCEE, V:85). Es decir, mientras la esposa esté guardando la casa, su amado le hablará por la ventana, pues aún un muro los separa. A pesar de este impedimento el esposo acerca su cabeza y por las celosías da una mirada hacia el interior. El autor explicará el sentido alegórico de esta frase, diciendo que la naturaleza humana se preparó para la unión con Dios por medio de los profetas y la ley. Las ventanas son los profetas que iluminan. Cancelas o celosías son los preceptos de la ley y a través de estos nos llega la luz de Dios. Empero, llegará el día en que acontecerá la plena iluminación, cuando aparezca la luz verdadera: Dios hecho hombre (CCEE V: 85). Gregorio comenta que ella aún desconoce lo que es infinitamente mayor; por eso el esposo se le aparece con frecuencia como si nunca le hubiese visto, prometiendo dejarse ver (CCEE XI: 171).

Según nuestro autor, la esposa desea vivamente su llegada en la carne, es decir, que el Verbo se haga hombre, aparezca Dios encarnado (CCEE V: 95). Anhela el día en el cual ya no sean necesarias las ventanas, puesto que la luz verdadera entrará con sus rayos evangélicos, iluminando a todo el mundo (CCEE V: 87). Al respecto Gargano (1981), ha indicado como punto de referencia indispensable y de justificación

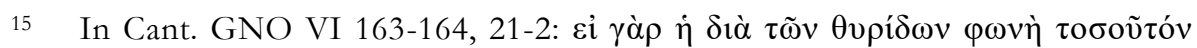

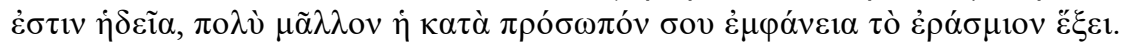


última de la exégesis Nisena la persona de Cristo; en su doble naturaleza de increado y creado, de espíritu y carne, de invisible y visible.

La esposa compara a Cristo esposo con el cervatillo, que no se deja ver ni está en un mismo lugar (CCEE VI: 102). Crecida en perfección, piensa que merece ver claramente el rostro del amado. Pues, ¿puede haber dicha mayor que ver a Dios? (CCEE VI: 102). Esta verdad es percibida en cuanto la esposa ha comprendido el misterio del evangelio. De este modo para Gregorio coincide el deseo de la esposa con las palabras de Simeón "Ahora, Señor, puedes, según tu palabra, que tu siervo se vaya en paz, porque han visto mis ojos tu salvación" (CCEE V: 95). Ella es la partícipe de los misterios divinos del esposo, después de ver su cámara convertida en palanquín del rey, se dirige a las doncellas - aquellas principiantes que se encaminan a la salvación-y dice:

¿Hasta cuándo vais a estar ocultas en la cueva? salid fuera de los velos de la naturaleza y, hechas hijas de Sión, ved este espectáculo admirable. Ved la corona bellísima en la cabeza del rey (CCEE VII: 119).

Según Sal 21,4 "coronaste su cabeza de oro fino". Para el autor, se trata de un solo desposorio, una sola esposa, una sola corona sobre la cabeza del esposo. Este es llamado Jesucristo el Hijo unigénito. Único esposo que vive en medio nuestro (CCEE VII: 120). De modo que, la esposa fiel a la voluntad de su Señor, a ejemplo de Abrahán, manda salir a las doncellas de su tierra, de su parentela, de lo que cae bajo los sentidos, para que vean al esposo con su corona ceñida. Por lo cual dice el Verbo: ¡Qué hermosa eres!, después que la vio transformada en su propia hermosura (CCEE VII: 120).

Gregorio intuye que el conocimiento de Dios parte del camino de la interioridad, pues Dios habita y se pasea dentro de nosotros, penetrando en lo más profundo del alma (CCEE III: 54), en esta perspectiva:

La vida buena es en parte visible y en parte íntima, que no se puede dar a entender a los demás, porque sólo Dios la ve. Aquel que ve las cosas antes de que existan, el que ve lo más recóndito da testimonio de que es más lo oculto en vida interior que lo visible exteriormente y dice así: Palomas son tus ojos a través de tu velo (CCEE VII: 122) ${ }^{16}$.

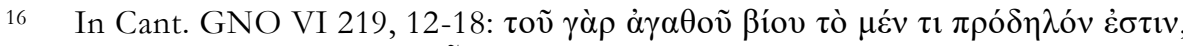

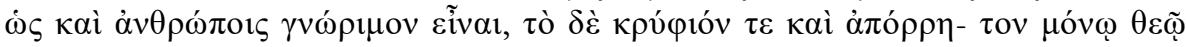

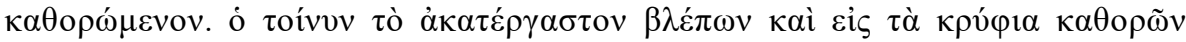

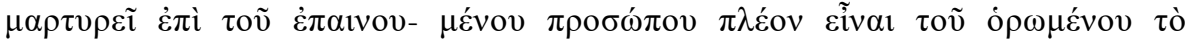

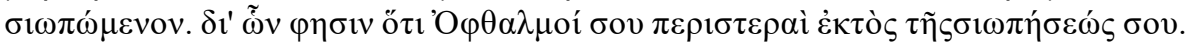


Para el autor, la acción de ver se encuentra supeditada al ojo, "se ve cuando las cosas visibles se presentan ante una pupila limpia" (CCEE VII: 122) y por los ojos se perfecciona el hombre interior y exteriormente. Ahora bien, esta experiencia es a través del velo, donde sólo Dios ve lo más recóndito. Según el Niseno dos cosas son ciertas: teniendo a Dios sobre nosotros también lo tenemos dentro y, recibiéndolo dentro, estamos a los pies del que mora en nosotros (CCEE III: 54). De tal forma, la clave que consolida y rige el método exegético de Gregorio de Nisa está constituida por la aceptación de la unicidad de Dios (CCEE XV: 249). Esta procede del Espíritu Santo, según Ef 4,4: "uno solo es el cuerpo y uno solo el Espíritu, como una es la esperanza a que habeís sido llamados". Comprendida en cuanto "todos sean uno. Como tú, Padre, en mí y yo en ti, que también sean uno en nosotros" (Jn 17,21). La que es anticipada por la Gloria en Jn 17,22-23:

Les he dado la gloria que me diste, para que sean uno, como nosotros somos uno: yo en ellos y tú en mí, para que sean perfectamente uno, y el mundo conozca que tú me has enviado y que los has amado a ellos como me has amado a mí.

Según M. Canévet (1988) se cuenta con dos textos particularmente consagrados al tema de la edificación de la unidad del cuerpo de Cristo, a saber, el tratado In illud Tunc et ipse Filius, que es un comentario de 1 Cor 15,28 y específicamente las Homilías XIV y XV del In Canticum. En esta línea, se sitúa el final del texto: Dios en todas las cosas por Cristo Jesús. De esta unidad emana la fuente de la omnipresencia de la gracia, presente en el creyente - en o encima de este-. Gregorio da a entender que la gracia es la misma, ya sea venga de arriba - Dios está encima- o penetra en el interior - Dios en el hombre-; en cuanto posibilidad otorgada por y en Cristo, quien lo inhabita (Meis, 1993:11). De modo que, frente a la incognoscibilidad de Dios, el hombre puede llegar a conocerle mediante la debilidad de la cruz. El Verbo se hizo carne, Cristo derrotó la fortaleza de su enemigo, entonces lo invisible se hizo visible; redimiendo a los cautivos y pagando por ellos el rescate: Cristo se entregó a la muerte como precio de nuestra redención, murió sin dejar de estar vivo y siendo esclavo está reinando (CCEE VIII: 140).

El In Canticum así lo deja entrever, pues quienes por la esposa vieron la hermosura del esposo, quedaron admirados al descubrirlo mediante lo visible. De modo, que a Dios "a quien nadie ha visto jamás", como dice san Juan, "a quien no ha visto ningún ser humano ni le puede ver" en la Iglesia y por la Iglesia - como cuerpo de Cristo- el que es cabeza, deja ver su rostro (CCEE VIII: 140). Gregorio, el Obispo de 
Nisa articula el sentido eclesial allí contenido según 1 Jn 4,12: mediante la comprensión de la Iglesia como cuerpo, la entrada en ella de aquellos que se salvan y la edifican en caridad. Es decir, a Cristo por la Iglesia:

Viéndola los amigos del esposo se entregan de corazón, pues al esposo, que es invisible, lo ven por aquello que es visible. Como los que no pueden mirar la redondez del sol lo ven por su reflejo en el agua, así aquellos también en espejo limpio, es decir, en la faz de la iglesia, ven al sol de justicia y por lo visible alcanzan a comprender (CCEE VIII: 141).

Entonces, en la faz de la iglesia, Cristo el que es cabeza deja ver su rostro y la naturaleza humana acercándose a Cristo, su imagen le quedará grabada. Fijará sus ojos en el bien, configurándose de ese modo a quien contempla, en la peculiar relación esponsal.

Sintetizando, a la esposa ya no le basta una mirada parcial, sino anhela mirar el rostro del esposo de modo definitivo. Ella desea vivamente su llegada en la carne, es decir, aparezca Dios encarnado, ver el rostro de Aquel. Gregorio comprende que los desposorios abren a la humanidad hacia una nueva condición. Se camina al tiempo en que habrá una sola esposa como un solo esposo, Jesucristo el Hijo unigénito, que vivirá en medio nuestro y por el cual, todos han sido llamados a ser perfectamente uno.

\section{CONCLUSIÓN}

El tema indagado en torno a la visión mística en Gregorio de Nisa, ha permitido detenernos en los principales conceptos de luz y ojo. Desde esta perspectiva, la luz se descubre en relación a la noche y ambos estadios, preparan a la esposa en la dinámica de mirar lo que permanece oculto. Conjuntamente, los sentidos adquieren relevancia, pues la introducen hacia una nueva comprensión; donde los ojos obtienen cierta preeminencia. Es destacable la relación análoga que establece el autor en torno a la búsqueda del alma con la noche; en este sentido se abre la pregunta de ¿cómo en la noche es más visible el invisible? Gregorio ha señalado el siguiente dinamismo presente en el In Canticum: el alma siente su presencia, pero no es posible que el entendimiento lo comprenda. De allí el alto alcance que obtienen los sentidos de la esposa, los cuales anticipan de algún modo la presencia del amado y la introducen en el misterio.

Por esta razón, ¿qué es lo que se ve? y ¿quiénes contemplan a Dios como El es? Según nuestro autor el simbolismo de los ojos se traduce en el más importante; aunque la esposa no pueda fijar los ojos en el 
Verbo, podrá ver al deseado. Por él recibe la luz y disfruta de buenos ojos permaneciendo en el bien. Entonces, su mirada puede llegar a ser una, teniendo un solo ojo, una sola alma de modo que pueda vivir centrada en una sola cosa.

Gregorio de Nisa intensifica en el In Canticum el tema de la unidad, en cuanto hay un solo Dios, y también un solo mediador. Con ello subraya uno de los dogmas cristológicos relevantes, en cuanto en Cristo no hay dos personas, sino la unión del hombre con la divinidad, por tanto, una persona. En esta expresión se configura el núcleo de su comprensión teológica y filosófica: "como un solo ojo, mirando al único bien". Tan solo si el ojo se hace puro como el candor de la paloma podrá acercarse al bien Amado. Es decir, aquel que está lleno de gracia, le será posible ver la hermosura del esposo. En esta consonancia se advierte que en la pupila de sus ojos están los de la esposa como palomas, recibiendo la semejanza de aquello en que fija sus ojos como imago Dei. Bajo este simbolismo el autor ha destacado el alto alcance de la mediación operada por Cristo. Una sola esposa como un solo esposo - Jesucristo el Hijo unigénito- que vive en medio nuestro.

\section{REFERENCIAS}

Abbagnano, N. (1991). Diccionario de filosofía. México: Fondo de Cultura Económica.

Acosta, J. (2017). Diccionario de Símbolos. (Ed. Bruno Rosario Candelier). Santo Domingo: Academia Dominicana de La Lengua.

Aristóteles (2011). Acerca del alma. (Introducción, traducción y notas de T. Calvo Martínez). Madrid: Biblioteca Básica Gredos.

Benedicto XVI (2007). Audiencia General, San Gregorio de Nisa. Disponible en http://w2.vatican.va/content/benedict-xvi/es/audiences/2007/documents/hf_ben-xvi_aud_20070829.html

Canévet, M. (1988). Qu'avons-nous en commun? Remarques sur le corps commun de 1'Eglise chez Grégoire de Nysse. Les Quatre Fleuves. Cabiers de recherche et de réflexion religieuses, 15-16(25-26), 49-56.

Campos, J. (2017). Diccionario de Símbolos. (Ed. Bruno Rosario Candelier). Santo Domingo: Academia Dominicana de La Lengua.

Denzinger, E. (1963). El Magisterio de la Iglesia. Barcelona: Herder.

De Nisa, G. (1993). Comentario al Cantar de los Cantares. (Edición preparada por T. H. Martín-Lunas). Salamanca: Sígueme.

Gargano, G. (1981). La teoria di Gregorio di Nissa sul Cantico dei Cantici. Indagine su alcune indicazioni di metodo esegetico. Roma: Orientalia Christiana Analecta.

Horn, G. (1927). Le "Miroir", la "Nuée". Deux maniéres de voir Dieu d' aprés S. Grégoire de Nysse. Revue d'Ascétique et de Mystique, 8(30), 113131. 
León-Dufour, X. (1965). Vocabulario de Teología Bíblica. Barcelona: Herder.

Mateo-Seco, L. F. (1990). La cristología del In Canticum Canticorum de Gregorio De Nisa. In H. Drobner-Ch. Klock (Eds.), Studien zu Gregoror von Nyssa und der christlichen Spätantike. Leiden: Vililiae Christianae Supplements.

Mateo-Seco, L. F. (1997). ¿Progreso o inmutabilidad en la visión beatífica? Apuntes de la Historia de la Teología. Scripta theologica, 29(1), 13-39.

Meis, A. (1993). Orígenes y Gregorio de Nisa, "In Canticum", CO VI, 607. VI Colloquium Origenianum International. Paris. Disponible en http://www.misticayrazon.cl/documentos/2011/documentos_ameis/019_Colloquium\%20origenianum-Paris.pdf

Nysseni, G. (1986). In Canticum Canticorum. (Edidit H. Langerbeck, En W. Jaeger (ed.), Volumen VI). Leiden: E. J. Brill.

Quasten, J. (2012). Patrología (II): La edad de oro de la literatura Patrística Griega. Disponible en http:/ / www.conoze.com/doc.php?doc $=5494$

Rodriguez, S. (2017). Diccionario de Símbolos. (Ed. Bruno Rosario Candelier). Santo Domingo: Academia Dominicana de La Lengua.

Sumario: Introducción; 1. Participación de los sentidos: luz y noche; 2. Fijar los ojos en el único bien; 3. Sus ojos como palomas; 4. Ver el rostro de Aquel; Conclusión; Referencias. 